\title{
Association of daily copayments with use of hospital care among medicare advantage enrollees
}

\author{
John P. McHugh ${ }^{1 *}$ D, Laura Keohane², Regina Grebla ${ }^{3}$, Yoojin Lee ${ }^{3}$ and Amal N. Trivedi' ${ }^{4,5}$
}

\begin{abstract}
Background: While the traditional Medicare program imposes a deductible for hospital admissions, many Medicare Advantage plans have instituted per-diem copayments for hospital care. Little evidence exists about the effects of changes in cost-sharing for hospital care among the elderly. Changing inpatient benefits from a deductible to a per diem may benefit enrollees with shorter lengths of stay, but adversely affect the out-of-pocket burden for hospitalized enrollees with longer lengths of stay.

Methods: We used a quasi-experimental difference-in-differences study to compare longitudinal changes in proportion hospitalized, inpatient admissions and days per 100 enrollees, and hospital length of stay between enrollees in MA plans that changed inpatient benefit from deductible at admission to per diem, intervention plans, and enrollees in matched control plans - similar plans that maintained inpatient deductibles. The study population included 423,634 unique beneficiaries enrolled in 23 intervention plans and 36 matched control plans in the 20072010 period.
\end{abstract}

Results: The imposition of per-diem copayments were associated with adjusted declines of 1.3 admissions/100 enrollees ( $95 \% \mathrm{Cl}-1.8$ to -0.9$), 6.9$ inpatient days/100 enrollees ( $95 \% \mathrm{Cl}-10.1$ to -3.8$)$ and 0.7 percentage points in the probability of hospital admission ( $95 \% \mathrm{Cl}-1.0$ to -0.4$)$, with no significant change in adjusted length of stay in intervention plans relative to control plans. For persons with 2 or more hospitalizations in the year prior to the cost-sharing change, adjusted declines were 3.5 admissions/100 (95\% Cl -8.4 to 1.4$), 31.1$ days/100 ( $95 \% \mathrm{Cl}-75.2$ to 13.0$)$ and 2.2 percentage points in the probability of hospitalization $(95 \% \mathrm{Cl}-3.8$ to -0.6$)$ in intervention plans relative to control plans.

Conclusions: Instituting per-diem copayments was associated with reductions in number of admissions and hospital stays, but not length of stay once admitted. Effects of inpatient cost-sharing changes were magnified for persons with greater baseline use of hospital care.

Keywords: Medicare advantage, Hospital utilization, Cost-sharing, Managed care

\footnotetext{
* Correspondence: jpm2192@cumc.columbia.edu

${ }^{1}$ Columbia University, Mailman School of Public Health, 722 West 168th

Street, 4th Floor, New York, NY 10032, USA

Full list of author information is available at the end of the article
}

(c) The Author(s). 2019 Open Access This article is distributed under the terms of the Creative Commons Attribution 4.0 International License (http://creativecommons.org/licenses/by/4.0/), which permits unrestricted use, distribution, and reproduction in any medium, provided you give appropriate credit to the original author(s) and the source, provide a link to the Creative Commons license, and indicate if changes were made. The Creative Commons Public Domain Dedication waiver (http://creativecommons.org/publicdomain/zero/1.0/) applies to the data made available in this article, unless otherwise stated. 


\section{Background}

Cost sharing is a common technique utilized by health insurers to "share" a portion of an enrollee's health expenditures with the enrollee. This often takes the form of a payment at the point of service (co-payment) or payment for a fixed percentage of the cost of a given health service (co-insurance). In the hospital setting, this could also be a lump sum payment at admission (a deductible), or a payment for each day in the hospital (a per diem) $[1,2]$.

The Medicare program has used cost sharing in various forms since its inception in 1965. Medicare enrollees are responsible for $20 \%$ coinsurance for physician visits and large inpatient deductibles for hospital admissions, with no cap on out-of-pocket spending. The role of cost sharing and its clinical and economic effects in the Medicare program are topics of ongoing health policy debate. A study of the commercially insured found substantial increases in hospital cost sharing from 2009 to 2013 [3].

There is relatively little evidence to guide policymakers about the impact of greater cost sharing in the Medicare program. The landmark RAND Health Insurance Experiment, a randomized trial of cost sharing in health care, found that persons with higher coinsurance rates used less care and had lower spending than those with more generous insurance [4]. However, the RAND experiment ended in 1982 and excluded the elderly, limiting its generalizability to contemporary Medicare beneficiaries. The imposition of an inpatient deductible in the United Mine Workers Health Plan in 1977 was associated with a 45\% decline in the probability of having a hospitalization [5]. Recent studies demonstrate that in response to increased outpatient copayments, Medicare beneficiaries reduced their use of outpatient services, but made greater use of hospital care $[6,7]$. To our knowledge, studies of the Medicare population related to incentives and cost sharing in the hospital have been limited to the Medigap program which provides supplemental insurance to cover inpatient deductibles and other copayments. These studies also find increased inpatient utilization for those experiencing decreased cost sharing through supplemental Medigap insurance [8-11]. There are important differences between Medicare Advantage and Medigap. Most Medigap policies eliminate inpatient cost sharing altogether, which is a much larger change than our study and presumably less relevant for Medicare Advantage, purchasing Medigap reduces or eliminates cost sharing for many other services besides inpatient care, and the effect of cost sharing may differ in Medicare Advantage given supply-side, managed care constraints that are not found in traditional Medicare. Recent studies related to Medicare and Medicare
Advantage focused on prescription drug use and adherence [12, 13], skilled nursing facility utilization [14], or Medicare Advantage enrollment [15]. The lack of inpatient utilization studies in the broader Medicare fee-for-service and Medicare Advantage programs is an important gap since hospital costs are the largest component of Medicare spending and the Medicare Part A deductible is the largest single out-of-pocket expense in the traditional Medicare benefit structure, $\$ 1340$ in 2018 [16]. Further, as there has been increasing policy interest in raising cost sharing in the traditional Medicare program to control spending, one strategy has been to reduce the generosity of supplemental plans and expose enrollees to first-dollar cost sharing, the findings in this study would help to inform the debate [17].

Medicare Advantage plans, which currently enroll 31\% of all beneficiaries, have experimented with changes to inpatient cost sharing [18]. A common change has been to eliminate the deductible and impose a daily copayment for each day of hospital care [19]. In 2010, "virtually all Medicare Advantage plans, 94\%, required enrollees to share in the costs of inpatient care. $81 \%$ percent imposed copayments, $2 \%$ imposed coinsurance, and $11 \%$ used both. Among Medicare Advantage plans charging copayments for inpatient care, $79 \%$ charged a copayment per day, $16 \%$ charged a copayment per stay, and 5\% charged both copayments per stay and per day." [20] A deductible is typically exceeded during the first day of a hospital stay, leaving no financial incentive for a patient to leave the hospital earlier. In contrast, a per diem structure retains an incentive for a patient to leave the hospital throughout his or her stay. Thus, changing a plan's benefit structure from a deductible to a per diem could mean lower out-of-pocket spending for beneficiaries with shorter lengths of stay, but greater out-ofpocket costs for hospitalized beneficiaries with longer lengths of stay, and subsequently could lead to decreased utilization. This study highlights the tradeoffs of this benefit change (potentially lower inpatient utilization but perhaps much higher cost-sharing requirements for sicker enrollees). In this study, we examined the impact of per-diem copayment and increased levels of cost sharing on the use of hospital care among Medicare Advantage enrollees age 65 and older. We hypothesized that changing the inpatient benefit structure from a deductible at admission to a per diem will result in reduced hospital utilization at the plan level.

\section{Methods}

Data source and study population

We obtained individual-level data from the Medicare Healthcare Effectiveness Data and Information Set (HEDIS) maintained by the Centers for Medicare and 
Medicaid Services (CMS) for the years 2007 through 2010. HEDIS contain individual-level data on Medicare Advantage (MA) enrollees' use of hospital care. Individuals were matched to the Medicare beneficiary summary file to determine their demographic characteristics. Monthly information on health plan benefits for all Medicare plans was used to identify each plan's costsharing requirement for inpatient hospitalizations. Information on health plan characteristics is publicly available on the CMS website.

We identified 33 plans that changed their inpatient benefit from a deductible at admission to a per diem (daily copayment), hereafter referred to as intervention plans. The intervention plans were identified across any two-year timeframe between 2007 and 2010 (e.g., 20072008, 2008-2009, or 2009-2010), with the intervention plans changing from a deductible in the first year of the two-year period to a per diem copayment in the second year of the two-year period. We found 223 plans that had no change in any inpatient or post-acute cost sharing across any one of the two-year timeframes between 2007 and 2010, hereafter referred to as control plans. Because changes in outpatient cost sharing can have an effect on hospital use and skilled nursing facility (SNF) or ambulatory care may substitute for hospital use, we limited the intervention and control plans to those that did not change, or made minimal change, to physician office or SNF cost sharing. Additionally, to mitigate any issues with co-insurance, we limited the intervention and control plans to those that did not impose co-insurance. In other words, the intervention plans imposed inpatient deductibles in year one and per diem copayments in year 2 whereas control plans imposed inpatient deductibles only in both years 1 and 2 .

From the 33 intervention plans and 223 control plans, we utilized 1:n matching to match on the basis of contract year, tax status (i.e., for-profit or not-for-profit), geography, and deductible amount. We required plans to match based on contract year and tax status. Then, matching was prioritized by state, contract, neighboring state, division, region, and baseline inpatient deductible. Of the 33 case plans, 28 were matched to control plans. We excluded 5 pairs with incomplete data across the two analysis years or pairs with low volume (less than 150 admissions) in either of the analysis years. Our final sample consisted of 23 intervention plans matched to 36 control plans.

From our initial sample of 565,075 unique individuals, we limited our sample to those beneficiaries 65 years of age and older, excluding 99,303 individuals (17.8\%), and who were not dually enrolled in Medicaid, excluding another 42,138 individuals (7.5\%), resulting in our main analytic sample of 423,634 unique individuals enrolled in the intervention and control plans during our observation period.

\section{Variables}

The main outcome variables were inpatient utilization as measured by inpatient admissions per 100 enrollees, inpatient days per 100 enrollees, proportion hospitalized and the mean length of stay. Length of stay was calculated as the total number of inpatient days divided by the total number of inpatient admissions.

The primary independent variables were an indicator variable for whether the health plan changed from an inpatient deductible to a per diem ( 1 for intervention and 0 for controls), an indicator variable for time (0 for the year before the intervention plans changed the inpatient benefit and 1 for the year after), and an interaction term between those variables.

We determined whether each individual received a Part D subsidy, which can serve as a proxy covariate for low income. Since we do not have individual level income, the Part D subsidy can serve as a valid substitute since Part D low-income subsidy recipients have limited assets and a maximum income of $150 \%$ of the federal poverty level [21]. Those receiving part D subsidies were subject to inpatient and outpatient copayments, since we excluded dual eligible enrollees.

Covariates included age category (65 to 74 years or older than 74 years), sex, race or ethnic group (black, white, other), and low-income Part D subsidy. To account for differences in plan benefits, we added the copayment amount for primary care and specialist office visits and the monthly premium amount. To account for any temporal trends in inpatient utilization, we also included a fixed effect for the calendar year.

\section{Analyses}

We used a difference-in-difference approach to assess the effect of plans changing from an inpatient deductible to a per diem benefit. This method accounts for time-invariant trends in outcomes by subtracting the change in inpatient utilization in control plans from the concurrent change in intervention plans that changed the inpatient cost-sharing benefit (hereafter referred to as difference-in-differences estimates) [22, 23].

We fitted one-part generalized linear models that included independent variables and covariates described above. We specified a negative binomial distribution and identity link for inpatient admissions and days per 100 enrollees and inpatient length of stay, and a binomial distribution for the proportion hospitalized. We ran each model using PROC GENMOD and clustered standard 
errors at the plan level to account for correlation among enrollees.

We conducted a sensitivity analysis that restricted the population to those who were continuously enrolled in the same plans for a full 24 months, the 12 months before and after the benefit change. These enrollees exhibited a much greater increase in utilization, perhaps indicating a sicker population with a higher likelihood of hospitalization in the second year. To account for exit and entrance of enrollees from health plans, we conducted an additional sensitivity analysis that considered all enrollees irrespective of the number of months of enrollment. Higher baseline utilization among these enrollees could be due to the inclusion of decedents who will often have high concentrations of hospital use at the end of life. Because there may be selection issues in the disenrollment from a plan, enrollment into a plan or the decision to stay in a plan based on the plan benefits, we also assessed the characteristics of enrollees that exited their plan, those that entered a plan after the intervention plans changed their benefit structures and those that remained with their plan as well as disenrollment rates from intervention and control plans.

To evaluate whether pre-policy trends in inpatient utilization were similar in intervention and control plans, we estimated difference-in-difference effects comparing annual changes in all outcomes during the two-year time period prior to the change in inpatient benefits. In other words, for an intervention plan that changed from a deductible in 2008 to a per diem in 2009, we analyzed the plan's differences in inpatient utilization between 2007 and 2008. None of the estimates reached conventional levels of statistical significance at the 95\% level. (Appendix Table 4) We also conducted a falsification test utilizing dual eligible enrollees that were excluded from our primary analysis since they are not subject to cost sharing. None of the estimates reached conventional levels of statistical significance at the 95\% level. (Appendix Table 5).

All analyses were performed with the use of SAS software, version 9.4. Results are reported with two-tailed $P$ values or $95 \%$ confidence intervals. Brown University's Human Research Protections Office and the CMS Privacy Board approved the study protocol.

\section{Results}

In the year before intervention plans replaced the inpatient deductible with a per-diem copayment, the average inpatient deductible in intervention plans was $\$ 376$ (interquartile range [IQR], $\$ 250$ to $\$ 500$ ) and in control plans was $\$ 349$ (IQR, $\$ 200$ to $\$ 600$ ). In the year after intervention plans changed their inpatient benefit, intervention plans replaced their inpatient deductible with a \$165 (IQR, \$110 to \$225) average daily copayment and the average inpatient deductible in control plans remained unchanged, by design. (Table 1) $71.6 \%$ of all hospitalized enrollees had only 1 inpatient admission in a given year, $18.6 \%$ had 2 inpatient admissions and the remaining $9.8 \%$ had 3 or more inpatient admissions in any given year. (Hospitalization data not reported in Table 1, but used to generate Fig. 1) The demographic characteristics of enrollees (e.g., age, sex, race, etc.) in the intervention and control plans were similar. (Table 1) Skilled nursing facility cost sharing was unchanged in the intervention and control plans. For outpatient cost sharing, intervention plans exhibited a $\$ 4$ increase in average specialist copayments and a $\$ 2$ increase in average primary care copayments compared to a $\$ 1$ decrease in average primary care copayments and no change in specialist copayments in the control plans. Emergency department copayments remained unchanged in the intervention and control plans. (Table 1) Average monthly premiums for intervention plans decreased slightly while control plan premiums remained stable. Intervention plans had a higher percentage of zero premium plans as compared to control plans. (Table 1).

Unadjusted inpatient admissions per 100 enrollees decreased in intervention plans by 0.4 admissions per 100 enrollees from the year before the benefit change to the year after the benefit change. In control plans, inpatient admissions per 100 enrollees increased by 1.1 admissions per 100 enrollees. Therefore, the difference-in-difference estimate of intervention plans relative to control plans was -1.4 admissions per 100 enrollees $(95 \% \mathrm{CI},-1.8$ to - 0.9). Adjusting for age, sex, race and Part D subsidy and including a year fixed effect resulted in a differencein-difference estimate of -1.3 admissions per 100 enrollees $(95 \% \mathrm{CI},-1.8$ to -0.9$)$ for intervention plans relative to controls. (Table 2).

We observed similar results for inpatient days per 100 enrollees and for the proportion of enrollees hospitalized. Unadjusted inpatient days per 100 enrollees in intervention plans decreased by -6.3 days per 100 enrollees relative to control plans $(95 \% \mathrm{CI},-9.3$ to 3.3) and the unadjusted proportion of enrollees hospitalized in intervention plans decreased by 1.0 percentage points relative to control plans $(95 \% \mathrm{CI},-1.3$ to -0.7). The adjusted difference-in-difference estimate of inpatient days per 100 enrollees in intervention plans relative to control plans was -6.9 days $(95 \% \mathrm{CI}$, -10.1 to -3.8$)$. The adjusted difference-in-difference estimate of the proportion of enrollees hospitalized in intervention plans relative to control plans was -0.7 percentage points $(95 \% \mathrm{CI},-1.0$ to -0.4$)$. Neither 
Table 1 Enrollee and Benefit Characteristics in Intervention and Control Plans

\begin{tabular}{|c|c|c|c|c|c|}
\hline \multirow[t]{2}{*}{ Variable } & \multicolumn{2}{|l|}{ Intervention Plans } & \multicolumn{2}{|l|}{ Control Plans } & \multirow{2}{*}{$\begin{array}{l}\text { All Plans } \\
\text { Yearly Average } \\
2007 \text { to } 2010\end{array}$} \\
\hline & $\begin{array}{l}\text { Year before deductible } \\
\text { to per diem change }\end{array}$ & $\begin{array}{l}\text { Year after deductible } \\
\text { to per diem change }\end{array}$ & $\begin{array}{l}\text { Year before intervention } \\
\text { plans changed benefit }\end{array}$ & $\begin{array}{l}\text { Year after intervention } \\
\text { plans changed benefit }\end{array}$ & \\
\hline \multicolumn{6}{|l|}{ Enrollee Characteristics } \\
\hline Enrollees & 182,452 & 216,549 & 267,774 & 291,546 & $4,261,061$ \\
\hline Hospitalized Enrollees & 26,731 & 30,356 & 38,353 & 43,350 & 664,112 \\
\hline Age $-y r$ & $75.3(6.9)$ & $75.0(7.0)$ & $75.6(6.8)$ & $75.6(7.0)$ & $74.4(7.0)$ \\
\hline Female sex - \% & 53.8 & 53.5 & 53.5 & 53.1 & 51.9 \\
\hline \multicolumn{6}{|l|}{ Race - \% } \\
\hline White & 89.3 & 89.3 & 90.4 & 90.4 & 84.7 \\
\hline Black & 5.8 & 5.8 & 4.0 & 4.0 & 8.8 \\
\hline Other & 5.0 & 5.0 & 5.6 & 5.6 & 6.6 \\
\hline Part D subsidy - \% & 4.1 & 4.2 & 4.6 & 4.5 & 5.4 \\
\hline \multicolumn{6}{|l|}{ Benefit Characteristics } \\
\hline Number of Plans & 23 & 23 & 42 & 42 & 1975 \\
\hline Average star rating & 2.9 & 2.6 & 2.8 & 2.9 & 2.9 \\
\hline Average \# of Enrollees & 7933 & 9415 & 6376 & 6942 & 2157 \\
\hline \multicolumn{6}{|l|}{ Plan Type } \\
\hline $\mathrm{HMO}$ & 91.3 & 91.3 & 69.0 & 69.0 & 53.0 \\
\hline PPO & 8.7 & 8.7 & 26.2 & 26.2 & 22.4 \\
\hline PFFS & 0.0 & 0.0 & 2.4 & 2.4 & 17.0 \\
\hline Other & 0.0 & 0.0 & 2.4 & 2.4 & 7.6 \\
\hline Mean deductible - $\$$ & $\$ 376$ & & $\$ 349$ & $\$ 349$ & $\$ 412$ \\
\hline Mean per diem (days 1-5) - \$ & & $\$ 165$ & & & $\$ 161$ \\
\hline Mean PCP copayment - $\$$ & $\$ 11$ & $\$ 13$ & $\$ 13$ & $\$ 12$ & $\$ 14$ \\
\hline Mean Spec. copayment - \$ & $\$ 21$ & $\$ 25$ & $\$ 21$ & $\$ 21$ & $\$ 25$ \\
\hline $\begin{array}{l}\text { Mean emergency department } \\
\text { copayment }-\$\end{array}$ & $\$ 50$ & $\$ 50$ & $\$ 49$ & $\$ 49$ & $\$ 49$ \\
\hline Zero premium plans - \% & 65.2 & 60.9 & 45.2 & 45.2 & 58.5 \\
\hline $\begin{array}{l}\text { Mean plan premium amount } \\
A / B-\$\end{array}$ & $\$ 20$ & $\$ 18$ & $\$ 31$ & $\$ 31$ & $\$ 24$ \\
\hline $\begin{array}{l}\text { SNF requires prior hospital } \\
\text { stay - \% of plans }\end{array}$ & 0.0 & 0.0 & 14.3 & 14.3 & 10.1 \\
\hline \multicolumn{6}{|c|}{ SNF benefits include cost sharing for first 20 days of SNF stay - $\%$ of plans } \\
\hline Coinsurance & 0.0 & 0.0 & 0.0 & 0.0 & 14.7 \\
\hline Deductible & 0.0 & 0.0 & 0.0 & 0.0 & 1.2 \\
\hline Copayment & 100.0 & 100.0 & 92.9 & 92.9 & 45.0 \\
\hline
\end{tabular}

unadjusted nor adjusted difference-in-difference estimates of mean length of stay reached conventional measures of significance at the $95 \%$ level. Results were similar when considering enrollees continuously enrolled for an entire 24-month period in the same plan and when examining beneficiaries enrolled for any amount of time. (Table 2).

We observed similar enrollee characteristics and inpatient utilization for beneficiaries staying enrolled in the same plan across intervention and control plans in the year prior to the benefit changes. We also see similar demographic characteristics among enrollees that exited plans in the year prior to exiting the plan and among enrollees that entered plans in the year prior to entering one of our study plans. A higher proportion of enrollees that exited intervention and control plans were hospitalized in the baseline year, $24 \%$, as compared to those enrollees remaining in the same plan, $11 \%$. There was no 


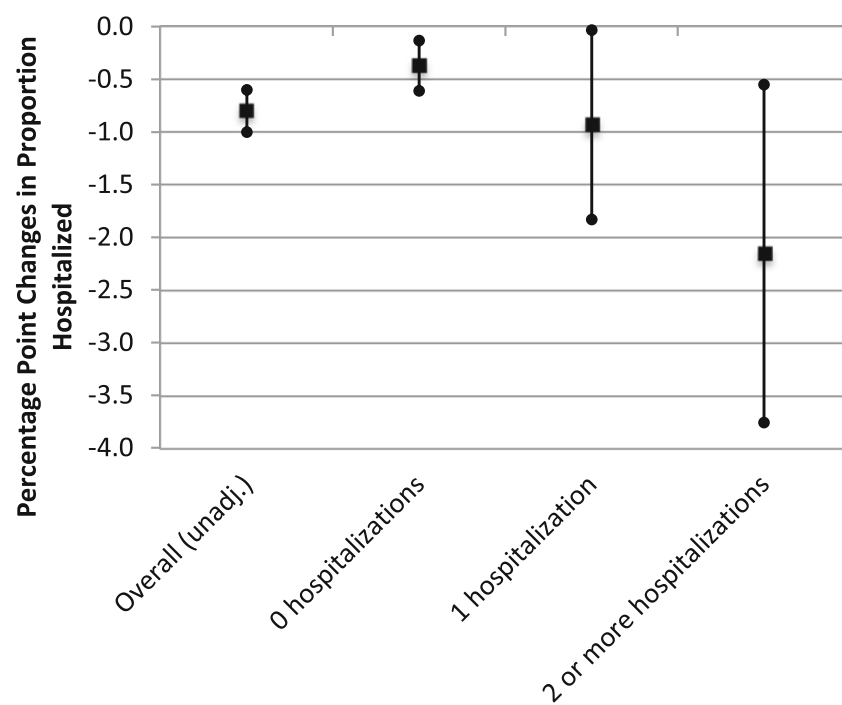

$95 \% \mathrm{Cl} \mathrm{High}$

95\% CI Low

- Proportion Hospitalized

Fig. 1 Difference-in-difference Estimates in the Proportion of Patients with a Hospital Admission, by the Number of Hospitalizations in the Year Before the Cost-sharing Change. Proportion Hospitalized (with 95\% Confidence Intervals)

Table 2 Use of Hospital Care in Intervention Plans that Replaced a Hospital Deductible with a Per-diem Copayment Compared to Concurrent Trends in Matched Control Plans that Maintained a Hospital Deductible

\begin{tabular}{|c|c|c|c|c|c|}
\hline \multicolumn{2}{|c|}{ Intervention Plans } & \multicolumn{2}{|l|}{ Control Plans } & \multicolumn{2}{|c|}{$\begin{array}{l}\text { Difference- in-Difference } \\
\text { Estimates }\end{array}$} \\
\hline $\begin{array}{l}\text { Year Before } \\
\text { Benefit Change }\end{array}$ & $\begin{array}{l}\text { Year After } \\
\text { Benefit Change }\end{array}$ & $\begin{array}{l}\text { Year Before } \\
\text { Intervention } \\
\text { Plan Changes }\end{array}$ & $\begin{array}{l}\text { Year After } \\
\text { Intervention } \\
\text { Plan Changes }\end{array}$ & Unadjusted & Adjusted \\
\hline
\end{tabular}

Beneficiaries enrolled for full 12 months in either year

per 100 enrollees

20.0

19.6

19.7

20.8

$-1.4^{* * *}(-1.8$ to -0.9$)$

$-0.9^{* *}(-1.4$ to -0.3$)$

Inpatient days

87.0

86.9

81.9

88.2

$-6.3^{* * *}(-9.3$ to -3.3$) \quad-4.2^{*}(-7.9$ to -0.5$)$

13.5

13.9

14.4

Mean inpatient length

4.0

4.1

4.0

4.0

$-1.0^{* * *}(-1.3$ to -0.7$)$

$-0.5^{* *}(-0.9$ to -0.1$)$

of stay

Beneficiaries enrolled for full 24 months in same plan

Inpatient admissions

24.4

per 100 enrollees

Inpatient days

per 100 enrollees

122.8

Proportion hospitalized (\%)

10.9

Average inpatient

4.5

length of stay

Beneficiaries enrolled for any amount of time

Inpatient admissions

28.5

per 100 enrollees

Inpatient days

153.2

per 100 enrollees

Proportion hospitalized (\%)

12.2

Average inpatient

4.9

length of stay
29.2

154.4

13.3

5.0

28.2

154.2

11.8

5.0

24.0

29.7

152.0

117.8

10.8

13.9

4.9

4.5

28.8

150.7

12.5

4.9

Note: All values are unadjusted, except those in the final column

${ }^{* * *} p<.0001,{ }^{* *} p<.01,{ }^{*} p<.05$
$30.0-1.5^{* * *}(-2.0$ to -1.0$) \quad-0.9^{* *}(-1.5$ to -0.4$)$

158.3

$-6.6^{* * *}(-10.0$ to -3.2$) \quad-3.6(-7.7$ to 0.6$)$

13.2

4.9

$-1.1^{* * *}(-1.4$ to -0.8$)$

$-0.5^{* *}(-0.9$ to -0.2$)$

$0.0(-0.1$ to 0.1$)$

$0.0(0.0$ to 0.1$)$ 
difference, though, when comparing intervention and control plans. Inpatient utilization for enrollees entering intervention and control plans in the year prior to entering was also similar. Beneficiaries disenrolled at a slightly higher rate from intervention plans, $16 \%$, as compared to control plans, $15.5 \%$. (Table 3 ).

For enrollees who were not hospitalized in their baseline year, the unadjusted difference-in-difference estimate of the proportion of enrollees hospitalized in intervention plans relative to control plans was -0.4 percentage points (95\% CI, -0.6 to -0.1$)$. For those enrollees hospitalized 1 time in their baseline year, the unadjusted difference-indifference estimate was -0.9 percentage points $(95 \% \mathrm{CI}$, -1.8 to -0.03$)$. Finally, for enrollees hospitalized 2 or more times in the baseline year, the unadjusted difference-in-difference estimate of the proportion of enrollees hospitalized in intervention plans relative to control plans was -2.2 percentage points $(95 \% \mathrm{CI}$, -3.8 to -0.6). (Fig. 1) Unadjusted difference-indifference estimates of admissions and days per 100 enrollees and average length of stay across strata of baseline hospitalizations did not reach conventional measures of significance at the $95 \%$ level.

\section{Discussion}

We studied the effect of changing an inpatient insurance benefit from a deductible at admission to a per diem (charge per day) in a large sample of Medicare Advantage enrollees age 65 and older. We found that the change in benefit structure was associated with significant declines in inpatient admissions and days per 100 enrollees. We also found a 0.7 adjusted percentage point reduction in the proportion of enrollees hospitalized in intervention plans relative to control plans. Enrollees with greater use of hospital care in the year prior to the cost-sharing change experienced greater declines in hospital utilization, perhaps indicating that patients, once hospitalized, were more acutely aware of the cost-sharing burden and took steps to avoid future admissions, or, perhaps, the plan itself more actively managed the patient to avoid additional inpatient expenses. Once enrollees were hospitalized, though, we did not find any significant difference in the adjusted length of stay between intervention and control plans.

Our findings are consistent with research on inpatient utilization and its association with supplemental Medigap insurance. Medigap coverage, or decreased cost sharing, has been found to be associated with increases in inpatient utilization, and we find a directionally similar result, with increased cost sharing associated with decreases in inpatient utilization, though it should be noted that the increased cost sharing only applies, on average, to patients hospitalized 3 days or more $(70.7 \%$ of hospitalized patients in our sample). Our findings are also broadly consistent with two studies of hospital cost sharing among non-elderly populations. The United Mine Workers Study demonstrated that the imposition of a $\$ 250$ hospital deductible in 1977 led to a " $45 \%$ decline in the probability of a hospital admission" from a baseline of $6.8 \%$, but resulted in an increase in length of stay among those hospitalized [5]. Our results show about a $7 \%$ relative reduction in the probability of a hospitalization from a baseline of about $20 \%$. The RAND experiment also found increases in cost sharing were associated with reductions in the likelihood of seeking

Table 3 Enrollee Characteristics and Utilization in Intervention and Control Plans for Beneficiaries Staying, Exiting and Entering Plans

\begin{tabular}{|c|c|c|c|c|c|c|c|c|c|c|c|}
\hline & $\begin{array}{l}\text { Disenrollment } \\
\text { Rate - \% }\end{array}$ & $\begin{array}{l}\text { Age - } \\
\text { yr (sd) }\end{array}$ & $\begin{array}{l}\text { Female } \\
\text { sex }-\%\end{array}$ & $\begin{array}{l}\text { White } \\
-\%\end{array}$ & $\begin{array}{l}\text { Black } \\
-\%\end{array}$ & $\begin{array}{l}\text { Other } \\
\text { race - \% }\end{array}$ & $\begin{array}{l}\text { Part D } \\
\text { subsidy } \\
-\%\end{array}$ & $\begin{array}{l}\text { Inpatient } \\
\text { Admissions per } \\
100 \text { enrollees }\end{array}$ & $\begin{array}{l}\text { Inpatient days } \\
\text { per } 100 \\
\text { enrollees }\end{array}$ & $\begin{array}{l}\text { Proportion } \\
\text { hospitalized } \\
(\%) \\
\end{array}$ & $\begin{array}{l}\text { Mean } \\
\text { inpatient } \\
\text { length of stay } \\
\end{array}$ \\
\hline \multicolumn{12}{|c|}{ Beneficiaries staying enrolled in same plan (utilization in period before benefit change in intervention plans) } \\
\hline $\begin{array}{l}\text { Intervention } \\
\text { Plans }\end{array}$ & $\mathrm{n} / \mathrm{a}$ & $\begin{array}{l}75.3 \\
(6.9)\end{array}$ & 53.6 & 89.1 & 6.0 & 4.9 & 4.2 & 24.4 & 122.8 & 10.9 & 4.5 \\
\hline Control Plans & $\mathrm{n} / \mathrm{a}$ & $\begin{array}{l}75.1 \\
(6.8)\end{array}$ & 52.4 & 91.2 & 4.0 & 4.8 & 4.0 & 24.0 & 117.8 & 10.8 & 4.5 \\
\hline \multicolumn{12}{|c|}{ Beneficiaries EXITING a plan (utilization in period before benefit change in intervention plans) } \\
\hline $\begin{array}{l}\text { Intervention } \\
\text { Plans }\end{array}$ & 16.0 & $\begin{array}{l}76.0 \\
(7.6)\end{array}$ & 51.8 & 86.9 & 7.0 & 6.1 & 4.9 & 40.2 & 222.5 & 24.0 & 5.3 \\
\hline Control Plans & 15.5 & $\begin{array}{l}77.4 \\
(7.5)\end{array}$ & 52.9 & 90.1 & 4.0 & 5.9 & 4.9 & 41.2 & 227.5 & 24.0 & 5.3 \\
\hline \multicolumn{12}{|c|}{ Beneficiaries ENTERING a plan in year after benefit change in intervention plans (utilization in period before entering plan) } \\
\hline $\begin{array}{l}\text { Intervention } \\
\text { Plans }\end{array}$ & $\mathrm{n} / \mathrm{a}$ & $\begin{array}{l}72.2 \\
(6.9)\end{array}$ & 52.0 & 88.1 & 6.3 & 5.6 & 4.7 & 15.3 & 59.8 & 10.8 & 3.7 \\
\hline Control Plans & $\mathrm{n} / \mathrm{a}$ & $\begin{array}{l}73.1 \\
(7.5)\end{array}$ & 51.0 & 89.6 & 5.5 & 4.8 & 4.2 & 14.5 & 59.1 & 10.3 & 3.9 \\
\hline
\end{tabular}


care, but not the intensity of care once the patient was hospitalized $[2,4]$. We also observe a reduction in the proportion hospitalized and reduction in inpatient admissions and days per 100 among enrollees exposed to the cost-sharing change. However, like the RAND study, we did not observe a corresponding increase in length of stay, perhaps because this outcome is more strongly influenced by the decisions of hospital physicians with relatively little impact by patients [24]. A central but often unappreciated finding from the RAND study is that cost sharing was not associated with reductions in the use of health services after patients initiate contact with the health care system.

Inpatient utilization remains the most expensive component of Medicare spending [25]. Therefore, if the purpose of the change in benefit structure was to reduce overall spending on hospital care, the intervention plans in our study likely achieved this objective by reducing aggregate inpatient utilization. However, there were substantial increases in out-of-pocket spending among hospitalized patients, particularly among patients with longer lengths of stay. For instance, a person with a median length of stay would experience expected out-ofpocket costs in the baseline year of $\$ 376$. In the year after the benefit change, the out-of-pocket costs for an enrollee in an intervention plan with a median length of stay of 4.4 days would increase by $93 \%$ to $\$ 726$. However, persons with longer lengths of stays would have substantially greater increases in out-of-pocket costs. For instance persons at the 75th percentile of length of stay (5.5 days) could expect to pay $\$ 908$ dollars for an admission after the cost-sharing changes went into effect, an increase of $141 \%$. This highlights the importance for Medicare Advantage enrollees, and for those helping consumers navigate the market, to understand the full package of benefits as it is quite possible some enrollees hospitalized after the benefit change were unaware of the higher copayment until after the hospitalization.

Strengths of our study include the use of a large sample of over 400,000 beneficiaries in 59 MA plans across the country. By observing the entire structure of each plans' benefit, we were able to identify plans that only changed their inpatient cost sharing, without making significant changes to skilled nursing facility, physician office or emergency department cost sharing. We matched plans by geographic region and confirmed that hospitalization utilization trends in intervention and control plans were similar prior to the change in cost sharing. To our knowledge, this is the first study to quantify the impact of changes in inpatient cost sharing among Medicare Advantage enrollees. We do, though, find greater cost sharing is associated with reduced inpatient utilization, similar to the studies done in the Medigap program.
Our study has limitations. First, we are unable to observe MA plans' strategies that, apart from changes in benefits, may have impacted hospital utilization. For instance, intervention plans may have implemented more stringent utilization management practices, or made changes in their network of preferred hospitals. However, this would assume that these strategies were implemented in intervention plans and not in control plans and occurred at the same time that inpatient cost sharing was changed. Second, hospitalization and length of stay decisions are complex and include many factors and decision makers, including physicians, care managers, other providers, and patients; our study did not directly observe these processes and exclusively relied on administrative data to quantify changes in inpatient utilization. Third, since traditional Medicare applies an inpatient deductible with no per diem, it would be difficult to generalize the findings to traditional Medicare beneficiaries. However, current policy debates related to cost sharing in the traditional Medicare program could benefit from these findings and, more broadly, the findings may also have implications for benefit design for other kinds of insurance, both public and private. Fourth, it is possible that enrollees selectively disenrolled from intervention plans, anticipating hospitalizations in the following year. However, we ran our regressions on enrollees that exited plans in the year they were included in our study and in the year after exiting one of our study plans and found no significant difference in utilization in our adjusted difference-in-difference models and in all but one (proportion hospitalized) of our unadjusted models. Fifth, we are limited in the covariates we have access to with our data, so there may have been substantial unobserved differences in key variables such as comorbidity and clinical complexity among enrollees in intervention and control plans that could have influenced our findings. However, we did not observe large baseline differences in hospital utilization between intervention and control plans, nor did we observe differences in utilization among those enrollees entering or exiting the intervention and control plans. Finally, we are limited to a small set of plans that met our matching criteria. There are differences between our study population and the overall Medicare Advantage population, therefore there are limits to the generalizability of our study. However, given the paucity of studies on this topic, this provides a foundation for future studies to better understand the effects of inpatient cost sharing on utilization.

\section{Conclusion}

In conclusion, we found that changing from a deductible to a per diem copayment structure was associated with reductions in utilization of inpatient care among 


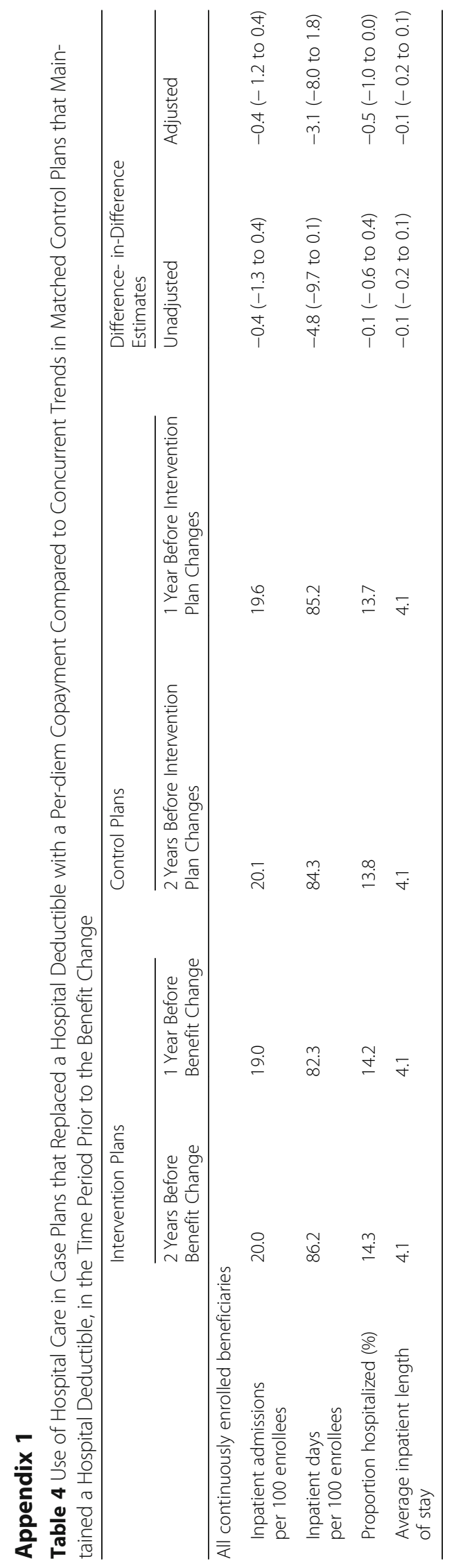




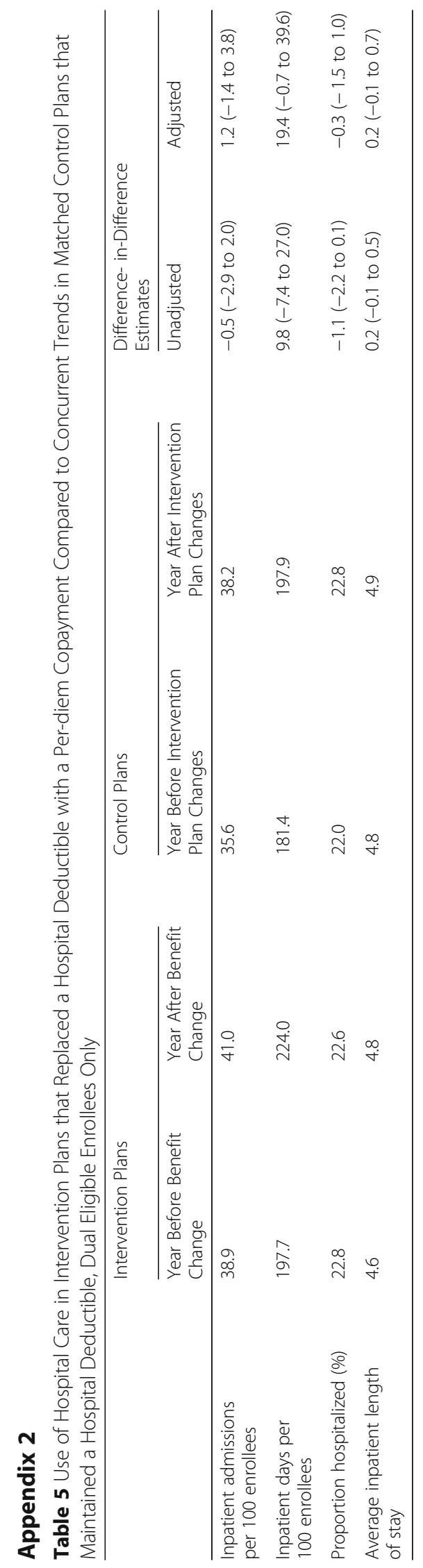


Medicare Advantage enrollees, particularly among those with greater use of hospital care prior to the copayment change. These reductions appear to be driven by decreases in the number of admissions and the probability of hospitalization, without significant changes in length of stay. Although the use of hospital care, but not the duration of admissions, may be sensitive to daily out-ofpocket costs, the financial burden of changing from a deductible to a per-diem falls heavily on seniors with longer hospital stays.

\section{Abbreviations}

Cl: Confidence Interval; CMS: Centers for Medicare and Medicaid Services; HEDIS: Healthcare Effectiveness Data and Information Set; HMO: Health Maintenance Organization; IQR: Interquartile Range; MA: Medicare Advantage; PCP: Primary Care Physician; PFFS: Private Fee-For-Service; PPO: Preferred Provider Organization; SNF: Skilled Nursing Facility

\section{Acknowledgements}

Not applicable.

\section{Authors' contributions}

JM analyzed and interpreted the data and was a major contributor in writing the manuscript. LK assisted in data analysis and interpretation and was a major contributor in writing the manuscript. RG was a major contributor in writing the manuscript. YL assisted in data analysis. AN assisted in data analysis and interpretation and was a major contributor in writing the manuscript. All authors have read and approved the manuscript

\section{Funding}

Funding for this study was provided by the National Institute on Aging (NIA) Program Project Grant P0-1 \#AG027296 and R0-1 \#AG044374.

The content is solely the responsibility of the authors and does not necessarily represent the official views of the NIA. The NIA was not involved in the design of the study, the collection, analysis, or interpretation of data, or writing the manuscript.

\section{Availability of data and materials}

The data that support the findings of this study are available from the Research Data Assistance Center (ResDAC) but restrictions apply to the availability of these data, which were used under license for the current study, and so are not publicly available.

\section{Ethics approval and consent to participate}

The Brown University Human Research Protections Office and the CMS Privacy Board approved the study protocol.

\section{Consent for publication}

Not applicable.

\section{Competing interests}

The authors declare that they have no competing interests.

\section{Author details}

${ }^{1}$ Columbia University, Mailman School of Public Health, 722 West 168th Street, 4th Floor, New York, NY 10032, USA. ²Department of Health Policy, Vanderbilt University School of Medicine, 2525 West End Avenue, Suite 1200, Nashville, TN 37203, USA. ${ }^{3}$ Center for Gerontology and Health care Research, Brown University, 121 South Main Street, Providence, RI 02903, USA. ${ }^{4}$ Department of Health Services Policy and Practice, Brown University, 121 South Main Street, Providence, RI 02903, USA. ${ }^{5}$ Providence Veterans Affairs Medical Center, 830 Chalkstone Avenue, Providence, RI 02908, USA.
Received: 29 July 2019 Accepted: 22 November 2019

Published online: 12 December 2019

\section{References}

1. Remler DK, Greene J. Cost-sharing: a blunt instrument. Annu Rev Public Health. 2009:30:293-311.

2. Swartz K. Cost-sharing: effects on spending and outcomes: Robert Wood Johnson Foundation; 2010

3. Adrion E, Ryan A, Seltzer A, Chen L, Ayanian J, Nallamothu B. Out-of-pocket spending for hospitalizations among nonelderly adults. JAMA Intern Med. 2016:176(9):1325-32.

4. Manning W, Newhouse J, Duan N, Keeler E, Leibowitz A. Health insurance and the demand for medical care: evidence from a randomized experiment. Am Econ Rev. 1987;77(3):251-77.

5. Scheffler R. The united mine Workers' health plan: an analysis of the costsharing program. Med Care. 1984;22(3):247-54.

6. Trivedi A, Moloo H, Mor V. Increased ambulatory care copayments and hospitalizations among the elderly. N Engl J Med. 2010;362(4):320-8.

7. Chandra A, Gruber J, McKnight R. Patient cost-sharing and hospitalization offsets in the elderly. Am Econ Rev. 2010;100(1):193-213.

8. Ettner S. Adverse selection and the purchase of Medigap insurance by the elderly. J Health Econ. 1997;16(5):543-62.

9. Keane M, Stavrunova O. Adverse selection, moral hazard and the demand for Medigap insurance. J Econ. 2016;190(1):62-78.

10. Dardanoni $V$, Donni P. Incentive and selection effects of Medigap insurance on inpatient care. J Health Econ. 2012;31(3):457-70.

11. Wolfe J, Goddeeris J. Adverse selection, moral hazard, and wealth effects in the Medigap insurance market. J Health Econ. 1991;10(4):433-59.

12. Pawaskar M, Xu L, Tang Y, Puckrein G, Rajpathak S, Stuart B. Effect of medication copayment on adherence and discontinuation in medicare beneficiaries with type 2 diabetes: a retrospective administrative claims database analysis. Diabetes Ther. 2018;9:1979-93.

13. McGee B, Phillips $V$, Higgins M, Butler J. Prescription drug spending and medication adherence among medicare beneficiaries with heart failure. J Manag Care Spec Pharm. 2019;25(6):705-13.

14. Keohane L, Grebla R, Rahman M, Mukamel D, Lee Y, Mor V, et al. First-dollar cost-sharing for skilled nursing facility care in medicare advantage plans. BMC Health Serv Res. 2017;17(1):611.

15. Meyers D, Belanger E, Joyce N, McHugh J, Rahman M, Mor V. Analysis of drivers of disenrollment and plan switching among Medicare advantage beneficiaries. JAMA Intern Med. 2019;179(4):524-32.

16. CMS. medicare.gov. [Online]; 2016 [cited 26 Oct 2016]. Available from: https://www.medicare.gov/your-medicare-costs/costs-at-a-glance/costs-atglance.html

17. Congressional Budget Office. Change the cost-sharing rules for medicare and restrict Medigap insurance. Washington, DC: Congressional Budget Office; 2013

18. Jacobson G, Casillas G, Damico A, Neuman T, Gold M. Medicare advantage 2016 spotlight: enrollment market update: Kaiser Family Foundation; 2016.

19. Gold M, Hudson M. Medicare advantage benefit design: what does it provide, what Doesn't it provide, and should standards apply? Washington, DC: Mathematica Policy Research, Inc.; 2009.

20. Gold M, Hudson M, Jacobson G, Neuman T. Medicare advantage 2010 data spotlight: benefits and cost-sharing: The Henry J. Kaiser Family Foundation; 2010.

21. Centers for Medicare and Medicaid Services. Guidance to states on the lowincome subsidy. Washington, DC: Centers for Medicare and Medicaid Services; 2009.

22. Campbell D, Stanley J, Gage N. Experimental and quasi-experimental designs for research. Chicago: Rand McNally; 1966.

23. Shadish W, Cook T, Campbell D. Experimental and quasi-experimental designs for generalized causal inference. Boston: Houghton Mifflin; 2001.

24. De Jong J, Westert G, Lagoe R, Groenewegen P. Variation in hospital length of stay: do physicians adapt their length of stay decisions to what is usual in the hospital where they work? Health Serv Res. 2006;41(2):374-94.

25. Cubanski J, Neuman T. The facts on medicare spending and financing: Issue Brief. The Henry J. Kaiser Family Foundation; 2016, July 20.

\section{Publisher's Note}

Springer Nature remains neutral with regard to jurisdictional claims in published maps and institutional affiliations. 